\title{
Sünnet İçin Başvuran Erkek Çocuklarda Anemi Prevalansı
}

\author{
Prevalence of Anemia in Boys Applying for Circumcision
}

(1)Elif Erdoğdu Ceylan1, @Nagihan Yıldız Çeltek², @Ufuk Ünlü², DOsman Demir³

'Boğazkale County State Hospital, Corum, Turkey

${ }^{2}$ Gaziosmanpasa University School of Medicine Department of Family Medicine, Tokat, Turkey

${ }^{3}$ Gaziosmanpasa University School of Medicine Department of Biostatistic, Tokat, Turkey

\section{$\ddot{\mathrm{OZZ}}$}

Amaç: Anemi, gelişmemiş ülkeler için önemli bir toplum sağlığı sorunudur. Görülme sıklığının sosyo-ekonomik düzeye bağlı olarak bölgeden bölgeye dahi değişebiliyor olması bu konuyla ilgili farklı bölgelerde yapılan çalışmaların kıymetini arttırmaktadır. Biz de bu çalışmamızda bir üniversite hastanesine sünnet için başvuran sağlıklı çocuklarda rastlantısal tespit edilen anemi prevalansını bulmayı amaçladık.

Gereç ve Yöntem: Çalışmamızda Ekim 2015-Ekim 2020 tarihleri arasında Tokat Gaziosmanpaşa Üniversitesi Tıp Fakültesi Hastanesi Üroloji Polikliniğine sünnet istemi ile başvuran 0-11 yaş aralığındaki çocukların işlem öncesi rutin bakılan tam kan tetkiki sonuçları retrospektif olarak değerlendirilmiştir.

Bulgular: Çalışmaya sünnet için başvuran 436 erkek çocuk dahil edilmiştir. Yaş ortalamaları 5,4 $\pm 3,2$ olarak bulunmuştur.

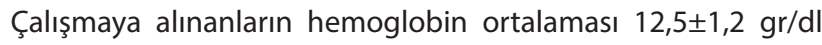
olarak bulunmuştur. Hemoglobin değerlerine göre $20(\% 4,6)$ çocukta anemi tespit edilmiştir. Anemi tespit edilen çocukların yaş ortalamaları 4,2 $\pm 4,4$ olarak hesaplanmıştır. Bu çocuklar yaş gruplarına göre değerlendirildiğinde 0-1 yaş grubunda 5 (\%25) kişi, 2-4 yaş grubunda 7 (\%35) kişi, 5-7 yaş grubunda 5 (\%25) kişi, 8-11 yaş grubunda 3 (\%15) kişi bulunmaktadır. RDW değeri \%12'den büyük hemoglobin ve MCV değerleri de yaşa göre düşük olan ve demir eksikliği anemisi lehine değerlendirilen 11 $(\% 2,5)$ çocuk tespit edilmiştir.

Sonuç: Anemi ülkemiz genelinde olduğu gibi bizim bölgemizde de sıkça görülen hastalıklardan biridir. Şikayeti olmayan çocuklarda dahi anemi tanısı konulabilmektedir. Hekimin bunu bilerek yaklaşması hastalığın erken tanı alması ve daha kolay tedavisi edilmesini sağlayacaktır.

Anahtar Kelimler: Anemi, prevalans, çocuk, sünnet

\section{ABSTRACT}

Aim: Anemia is an important public health problem for underdeveloped countries. The incidence varies from region to region, because of this, studies in different regions are valuable. In this study, we aimed to find the incidentally detected anemia rate in children who applied to a university hospital for circumcision.

Material and Method: In our study, the routine hemogram test results of aged 0-11 who applied to the Urology Polyclinic of Tokat Gaziosmanpaşa University Medical Faculty Hospital between October 2015 and October 2020 with a request for circumcision were retrospectively evaluated. 436 boys who applied for circumcision were included in the study. Their average age was found to be $5.4 \pm 3.2$. The average hemoglobin value of the subjects included in the study was calculated as $12.5 \pm 1.2 \mathrm{gr} /$ dl. According to hemoglobin values, anemia was detected in 20 (4.6\%) children.

Results: The mean age of children with anemia was calculated as $4.2 \pm 4.4$. When these children are evaluated according to age groups, 5 (25\%) children in the 0-1 age group, 7 (35\%) children in the 2-4 age group, 5 (25\%) children in the 5-7 age group, 3 (15\%) in the 8-11 age group there are children. Children with RDW values greater than $12 \%$ and also lower HGB and MCV values for age were considered to have iron deficiency anemia. According to these criteria, 11 (2,5\%) patients had iron deficiency anemia.

Conclusion: Anemia is one of the common diseases in our region as well as in our country. The fact that it is seen even in children without any complaints shows that anemia should always be kept in mind. This will facilitate early diagnosis and treatment.

Keywords: Anemia, prevalence, children, circumcision 


\section{GIRIŞ}

Anemi, hemoglobin (HGB) değerinin yaşa ve cinsiyete göre olması gereken değerden 2 standart deviasyon (SD) daha düşük olması şeklinde tanımlanabilir (1). Özellikle gelişmekte olan ve gelişmemiş ülkelerde önemli sağlık sorunlarının başında yer almaktadır (2). Gelişmekte olan ülkelerde 5 yaşından küçük çocuklarda anemi prevalansı $\% 52$ iken, gelişmiş ülkelerde bu oran \%12'lere kadar düşmektedir (3). Dünya Sağlık Örgütü (DSÖ)'nün raporuna göre tüm dünyadaki okul çağı çocuklarının yaklaşık $\% 49$ 'u anemiden etkilenmektedir (4). Ülkemizde yapılan bir çalışmada 6-11 yaş arasındaki okul çağı çocuklarında anemi prevalansının \%28 olduğu tespit edilmiştir (5).

Tüm dünyada olduğu gibi ülkemizde de aneminin en sık sebebi demir eksikliği anemisidir. DSÖ tüm dünya nüfusunun\%24,8'indedemireksikliği anemisigörüldüğünü düşünmektedir (6). Yine DSÖ'nün 2011 verilerinde ülkemizdeki okul öncesi çocuklarının \%32,6'sında demir eksikliği anemisi görüldüğğ bildirilmiştir (7). Demir eksikliği anemisi kesin tanısı için altın standart kemik iliği biyopsisi olmasına rağmen, işlemin zorluğu nedeniyle genellikle demir, demir bağlama kapasitesi, ferritin düzeyleri tanı için destekleyici olarak kullanılmaktadır. Bunun dışında düşük ortalama korpüsküler hacim (MCV) ve artmış eritrosit dağılım hacmi (RDW)'nin bir arada görülmesi kabul görmüş bir tarama yöntemidir (8).

Özellikle çocukluk çağında görülen anemi mental ve motor gelişim üzerine olumsuz etkiler bırakmaktadır. Bu olumsuz etkilerin anemi tedavisinden sonra dahi düzelmemesi aneminin erken dönemde tanı ve tedavisinin önemini arttırmaktadır $(9,10)$.

Biz bu çalışmamızda Tokat ilinde herhangi bir şikayeti olmayan ve sünnet için başvuran sağlıklı çocuklarda, rutin bakılan kan tetkiklerinde rastlanılan çocukluk çağı anemisi oranlarını tespit etmeyi amaçladık.

\section{GEREÇ VE YÖNTEM}

Çalışmanın örneklem grubunu Ekim 2015-Ekim 2020 tarihleri arasında Tokat Gaziosmanpaşa Üniversitesi Tıp Fakültesi Hastanesi Üroloji Polikliniğine sünnet istemi ile başvuran 0-11 yaş aralığındaki hastalar oluşturmaktadır. Sünnet öncesi değerlendirmede hemogram istemi yapılan çocuklar örnekleme dahil edilmiş, hemogram istemi yapılmamış çocuklar örneklem grubunun dışında bırakılmışıtır. Sünnet işlemi öncesi rutin olarak bakılan hemogram testi sonuçları retrospektif olarak değerlendirmeye alınmıştır. Hastalara ait hemoglobin (HGB), hemotokrit (HCT), ortalama eritrosit hacmi (MCV), ortalama eritrosit hemoglobin değeri $(\mathrm{MCH})$, ortalama eritrosit hemoglobin konsantrasyonu (MCHC) ve eritrosit dağılım genişliği (RDW) değerlendirilmiştir. Hemoglobin değeri yaşa ve cinsiyete uygun referans değerinin alt sınırından düşük olanlar (2 standart deviasyon, -2 SD ve altı) anemi olarak tanımlanmıştır. MCV, HTC değerleri için alt sınır yaşa uygun referans değerinin alt sınırından düşük (2 standart deviasyon, -2 SD ve altı) olarak belirlenmiştir. RDW için referans değer \%12 olarak kabul edilmiştir (Tablo 1) (11).

Çalışma gruplarının genel özellikleri hakkında bilgi vermek amacı ile tanımlayıcı analizler yapılmıştı. Sürekli değişkenlere ait veriler ortalama \pm standart sapma şeklinde; kategorik değişkenlere ilişkin veriler ise $n$ (\%) şeklinde verilmiştir. Nicel değişkenlerin gruplar arasındaki ortalamalarını karşış̧̧ııııken İki Ortalama Arasındaki Farkın Önemlilik testi ve Tek Yönlü Varyans Analizinden yararlanılmıştır. Nitel değişkenler arasındaki ilişki olup olmadığını değerlendirmek için çapraz tablolardan ve ki-kare testlerinden yararlanılmıştır. $p$ değerleri 0.05 'den küçük hesaplandığında istatistiksel olarak anlamlı kabul edilmiştir. Hesaplamalarda hazır istatistik yazılımı kullanılmıştır (SPSS 22.0 Chicago, IL, USA).

Çalışma için Tokat Gaziosmanpaşa Üniversitesi Tıp Fakültesi klinik araştırmalar etik kurulundan (21-KAEK061) ve Üroloji Kliniği Anabilim Dalı başkanlığından izin alınmıştır.

\section{BULGULAR}

Çalışmaya sünnet için başvuran 436 erkek çocuk dahil edilmiştir. Yaş ortalamaları 5,42 $\pm 3,16$ olarak bulunmuştur. Yaş gruplarına göre ayrıldığında 0-1 yaş aralığında 64 $(\% 14,7), 2-4$ yaş aralığında $86(\% 19,7), 5-7$ yaş aralığında 191 (\%43,8), 8-11 yaş aralığında $95(\% 21,8)$ çocuk olduğu görülmüştür (Tablo 2).

\begin{tabular}{|c|c|c|}
\hline Yaş Grupları & n(sayı) & \%(yüzde) \\
\hline 0-1 Yaş & 64 & 14,7 \\
\hline 2-4 Yaş & 86 & 19,7 \\
\hline 5-7 Yaş & 191 & 43,8 \\
\hline 8-11 Yaş & 95 & 21,8 \\
\hline
\end{tabular}

\begin{tabular}{|c|c|c|c|c|c|c|}
\hline \multirow{2}{*}{ Yaş } & \multicolumn{2}{|c|}{ Hemoglobin (HGB) (gr/dl) } & \multicolumn{2}{|c|}{ Hematokrit (HCT) (\%) } & \multicolumn{2}{|c|}{ Ortalama korpüsküler hacim (MCV) (ff) } \\
\hline & Ortalama & $-2 S D$ & Ortalama & $-2 S D$ & Ortalama & $-2 S D$ \\
\hline 6 ay- 2 yaş & 12,5 & 11,0 & 37,0 & 33,0 & 77,0 & 70,0 \\
\hline $2-4$ yaş & 12,5 & 11,0 & 38,0 & 34,0 & 79,0 & 73,0 \\
\hline 5-7 yaş & 13,0 & 11,5 & 39,0 & 35,0 & 81,0 & 75,0 \\
\hline 8-11 yaş & 13,5 & 12,0 & 40,0 & 36,0 & 83,0 & 76,0 \\
\hline 12-17 yaş (Erkek) & 14,0 & 12,5 & 43,0 & 37,0 & 84,0 & 77,0 \\
\hline
\end{tabular}


Çalışmaya alınanların HGB değerleri ortalaması $12,54 \pm 1,15 \mathrm{gr} / \mathrm{dl}$ olarak bulunmuştur. Yaş grupları ile $\mathrm{RBC}, \mathrm{HGB}, \mathrm{HCT}, \mathrm{MCV}, \mathrm{RDW}$ değerleri arasında istatiksel olarak anlamlı bir ilişki bulunmuştur $(p<0,01)$. Nicel değişkenlerin yaş gruplarına göre dağılımı Tablo 3 de gösterilmiştir.

Hastaların HGB değerleri yaşlarına göre değerlendirildiğinde düşük HGB değerine sahip 20 $(\% 4,6)$ çocuk tespit edilmiştir. Anemi saptanan bu

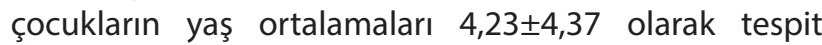
edilmiştir. HGB değerleri çocukların yaş gruplarına göre değerlendirildiğinde en sık 2-4 yaş aralığında anemi görülmüştür. Anemi ile yaş grupları arasında anlamlı bir ilişki bulunamamıştır.

MCV değeri yaşa göre düşük olarak bulunan 105 (\%24,1) çocuk tespit edilmiştir. Bunların yaş gruplarına göre dağılımına bakıldığında en sık 5-7 yaş aralığında 44 $(\% 10,1)$ çocuk görülmüştür. MCV değerleri ile yaş grupları arasında anlamlı bir ilişki bulunamamıştır. Anemili grupta 10 (\%50) çocuğun MCV değerlerinin de düşük olduğu izlenmiştir.

HTC değeri yaşa göre düşük bulunan 94 (\%21,5) çocuk bulunmuştur. Bu çocuklar yaş gruplarına göre değerlendirildiğinde en sık 5-7 yaş aralığında $35(\% 8,1)$ çocuk görülmüştür. HTC değerleri ile yaş grupları arasında anlamlı bir ilişki saptanmıştır $(p<0,01)$. HGB değeri düşükken HTC değeri de düşük olan 18 (\%90) çocuk bulunmuştur. Çalışmaya alınan çocukların RDW

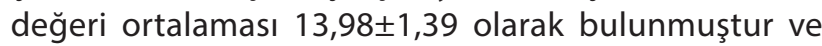
bunun yaşlara göre dağılımı Tablo 3'de gösterilmiştir. RDW değeri \%12'den büyük olan 11 çocuk tespit edilmiştir ve bunların yaş gruplarına göre dağılımı Tablo 4'de gösterilmiştir. Bunlardan HGB ve MCV değerleri de yaşa göre düşük olan ve demir eksikliği anemisi olarak değerlendirilebilecek 11 çocuk tespit edilmiştir. Pearson ki-kare testi kullanıldı.

\section{TARTIŞMA}

Anemi, çocukluk çağı hastalıkları arasında önemli bir yer kaplar. Aneminin sebep olduğu kalıcı beyin hasarına bağlı ortaya çıkan mental ve motor sekellerin anemi tedavisinden sonra dahi düzelmemesi erken tanı ve tedavinin önemini ortaya koymaktadır (12). Aneminin görülme sıklığı gelişmişlik düzeyi, cinsiyet, yaş ve coğrafi konuma göre değişmektedir $(13,14)$.

Anemi semptomları hastalığın başlangıcında silik ya da non-spesifik olabilmektedir. Bu nedenle bu çalışma hiçbir şikayeti olmayan olguların verileriyle gerçekleştirilmiştir.

Literatürde benzer çalışmalar bulunmaktadır. 2012 yılında Sivas'ta 1-15 yaş grubunda benzer şekilde retrospektif olarak yapılan bir çalışmada anemi prevalansı \%5,9 olarak bulunmuştur (15). Samsun ilinde 2017-2018 yıları arasında üniversite hastanesine başvuran 0-15 yaş grubu çocuklarla yapılan bir çalışmada ise anemi prevalansı \%8,2 olarak bulunmuştur (16). İstanbul'da 2011 yılında sünnet için başvuran 450 erkek çocuk ile retrospektif olarak yapılan çalışmada ise anemi prevalansı \%6,4 olarak bulunmuştur (17). Bizim çalışmamızda bu oran $\% 4,6$ olarak bulunmuştur. Bölge olarak yakın olduğumuz bu illerde birbirinden farklı sonuçlar çıkmasının en büyük nedeni anemi prevalansının sosyoekonomik düzeyle ilişkili olarak değişmesidir. Aynı zamanda yıllar içinde demir eksikliği anemisi ile ilgili farkındalığın artması ve ülkemizde uygulanan demir profilaksisi uygulaması sonucunda anemi prevalansının düştüğü öngörülmektedir.

Tablo 3. Yaş gruplarına göre nicel değişkenler dağılımı

\begin{tabular}{|c|c|c|c|c|c|}
\hline \multirow{3}{*}{ Değişkenler } & \multicolumn{4}{|c|}{ Yaş Grupları } & \multirow{3}{*}{$\mathbf{p}$} \\
\hline & $0-1$ & $2-4$ & $5-7$ & 8-11 & \\
\hline & Ort $\pm S S$ & Ort $\pm S S$ & Ort $\pm S S$ & Ort $\pm S S$ & \\
\hline $\mathrm{RBC}$ & $4,53 \pm 0,49$ & $4,73 \pm 0,4$ & $4,81 \pm 0,35$ & $4,94 \pm 0,4$ & $<0,001$ \\
\hline $\mathrm{HGB}(\mathrm{gr} / \mathrm{dl})$ & $11,67 \pm 1,47$ & $12,03 \pm 1$ & $12,69 \pm 0,88$ & $13,27 \pm 0,95$ & $<0,001$ \\
\hline HCT(\%) & $34,35 \pm 4,21$ & $35,23 \pm 2,79$ & $36,96 \pm 2,47$ & $38,59 \pm 2,57$ & $<0,001$ \\
\hline$M C V(f)$ & $76,17 \pm 7,84$ & $74,7 \pm 4,59$ & $77,02 \pm 3,58$ & $78,4 \pm 4,74$ & $<0,001$ \\
\hline RDW(\%) & $14,9 \pm 2,06$ & $14,26 \pm 1,35$ & $13,77 \pm 1,07$ & $13,51 \pm 1,08$ & $<0,001$ \\
\hline
\end{tabular}

Tablo 4. Yaş gruplarına göre nitel değişkenler dağılımı

\begin{tabular}{|c|c|c|c|c|c|c|}
\hline \multirow{2}{*}{ Değişkenler } & & \multicolumn{4}{|c|}{ Yaş grupları } & \multirow{2}{*}{$\mathbf{P}$} \\
\hline & & 0-1 n (\%) & 2-4 n (\%) & 5-7 n (\%) & 8-11 n (\%) & \\
\hline \multirow{2}{*}{$\mathrm{HGB}(\mathrm{gr} / \mathrm{dl})$} & Düşük & $5(1,2)$ & $7(1,6)$ & $5(1,2)$ & $3(0,7)$ & \multirow{2}{*}{0,105} \\
\hline & Normal & $59(13,5)$ & $79(18,1)$ & $186(42,6)$ & $92(21,1)$ & \\
\hline \multirow{2}{*}{$\mathrm{HCT}(\%)$} & Düşük & $28(6,4)$ & $24(5,5)$ & $35(8,1)$ & $7(1,6)$ & \multirow{2}{*}{$<0,001$} \\
\hline & Normal & $36(8,3)$ & $62(14,2)$ & $156(35,8)$ & $88(20,1)$ & \\
\hline \multirow{2}{*}{$\operatorname{MCV}(f)$} & Düşük & $14(3,2)$ & $18(4,1)$ & $44(10,1)$ & $29(6,7)$ & \multirow{2}{*}{0,406} \\
\hline & Normal & $50(11,5)$ & $68(15,6)$ & $147(33,7)$ & $66(15,1)$ & \\
\hline
\end{tabular}


Yapılan çalışmalarla aneminin en sık 5 yaş altı çocuklarda görüldüğü ve 5 yaş altı anemi oranın gelişmiş ülkelerde \%12, gelişmekte olan ülkelerde ise \%51 olduğu tespit edilmiştir (18). Ülkemizde yapılan bir çalışmada ise 2-5 yaş arası çocuklarda anemi sıklığı \%7 olarak bulunmuştur (19). Ülkemizde yapılan benzer bir çalışmada en sık görülen yaş grupları 1-3 yaş $(\% 8,1)$ ve $13-15$ yaş $(\% 8,9)$ olarak tespit edilmiştir (15). Bizim çalışmamızda da benzer şekilde anemi sıklığı 0-4 yaş grubunda en yüksek bulunmuştur (Grafik 1). Bu yaş grubunda büyüme ve gelişmenin hızlı olması ve demirden yoksun beslenme anemi etiyolojisinde ilk akla gelen sebeplerdir. İlk 6 ay içerisinde anne sütünden alınan demirin emilimi inek sütünü oranla yüksektir. Fakat ek gıda döneminde demirden eksik beslenme ve fazla inek sütü tüketimi bu yaş grubunda demir eksikliğine bağlı anemi görülme sıklığını arttırmaktadır (20). Bizim çalışmamız yalnızca erkek çocuklar üzerinde yapıldığı için 13-15 yaş arasında görülen anemi oranındaki artışın bizim çalışmamızda görülmediği düşünülmektedir. Çünkü bu yaş grubunda kız çocuklarında menarşın başlamasıyla kanamaya bağlı meydana gelen demir eksiliği nedeniyle anemi oranlarının arttığı düşünülmektedir.

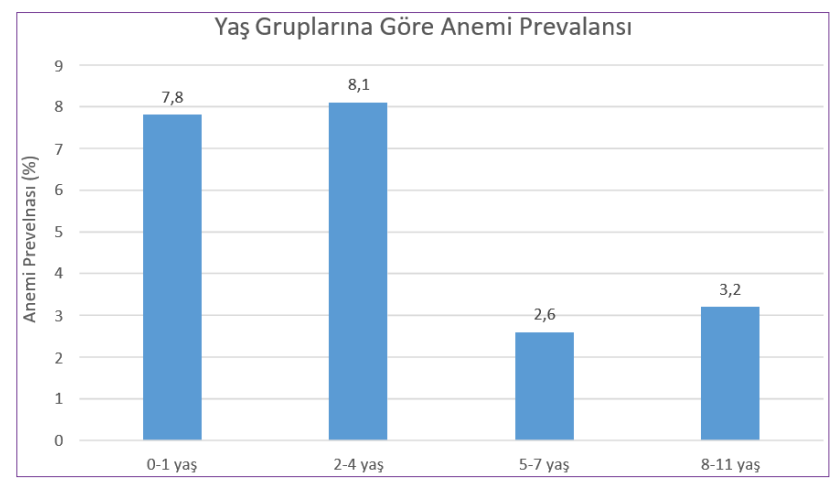

Grafik 1. Yaş Gruplarına Göre Anemi Prevalansı

Anemi nedenlerine bakıldığında demir eksikliği anemisi tüm dünyada olduğu gibi ülkemizde de ilk sırada yer almaktadır. Samsun ilinde yapılan benzer bir çalışmada demir eksikliği anemisi oranı \%28 olarak bulunmuştur (16). Ülkemizde poliklinik kayıtları incelenerek adölesanlar üzerinde yapılan benzer bir çalışmada demir eksikliği anemisi prevalansı \%17-30 oranında bulunmuştur (14). Şanlıurfa'da 6-16 yaş arası çocuklarda yapılan bir çalışmada anemi saptananların \%58,9'unun demir eksikliğine bağlı olduğu tespit edilmiştir (21). Yapmış olduğumuz çalışmada anemisi olup MCV değeri düşük, RDW değeri \%12'den yüksek olan hastalar demir eksikliği anemisi lehine değerlendirilmiştir. Bu şekilde DEA lehine değerlendirilen hasta prevalansı $\% 2,5$ olarak tespit edilmiştir.

Anemi çocukluk yaş grubunun sık görülen hastalıklarından biridir. Demir eksikliği anemisi de dahil olmak üzere tüm anemilerde ikincil klinik bulgular görülebileceği gibi hiç klinik bulgu olmadan laboratuvar testi sırasında da tanı alabilir. Tüm sistemler üzerine etkisi olduğu bilinmekle birlikte en çok nörokognitif sistem etkileri üzerinde durulmaktadır (21). Prospektif yapılan bazı çalışmalar anemisi olan çocuklarda motor gerilik, bilişsel gerilik ve duygulanım bozuklukları görülebildiğini göstermektedir (22).

Ülkemizde son yıllarda demir eksikliği anemisine ilişkin farkındalığının artması demirden zengin beslenmeyi teşvik etmiştir. Bununla birlikte Sağlık Bakanlığının profilaktik demir preparatları kullanımı politikası ile erken yaşlarda görülen aneminin önlenmesi sağlanmıştır. Yapılan bir çalışma profilaktik demir kullanımının 6 aylık bebeklerde anemi oranını \%30'dan \%2'ye düşürdüğünü göstermektedir (23).

\section{SONUÇ}

Tüm bu gelişmelerle birlikte anemi ülkemiz için çocukluk çağının en sık rastlanılan hastalıklarından biri olmaya devam etmektedir. Semptomların silik olması tanıyı zorlaştırmaktadır. Bu nedenle hekimlerin sürekli anemi tanısını akılda tutmasını gerekmektedir. Ailelere gerekli bilgilerin sık sık verilmesi beslenme önerilerinde bulunulması gerekmektedir. Sonuç olarak biz de şikayeti olmayan çocuklarda dahi anemi saptanabileceği ve bunun erken tanı için önemli olduğunu ortaya koymak ve buna dikkat çekmek istedik

\section{ETIK BEYANLAR}

Etik Kurul Onayı: Çalışma için Tokat Gaziosmanpaşa Üniversitesi Tıp Fakültesi klinik araştırmalar etik kurulundan (21-KAEK- 061) ve Üroloji Kliniği Anabilim Dalı başkanlığından izin alınmıştır.

Aydınlatılmış Onam: Çalışma retrospektif olarak dizayn edildiği için hastalardan aydınlatılmış onam alınmamıştır.

Hakem Değerlendirme Süreci: Harici çift kör hakem değerlendirmesi.

Çıkar Çatışması Durumu:Yazarlar bu çalışmada herhangi bir çıkara dayalı ilişki olmadığını beyan etmişlerdir.

Finansal Destek: Yazarlar bu çalışmada finansal destek almadıklarını beyan etmişlerdir.

Yazar Katkıları: Yazarların tümü; makalenin tasarımına, yürütülmesine, analizine katıldığını ve son sürümünü onayladıklarını beyan etmiş̧lerdir.

\section{KAYNAKÇA}

1. Dallmon Pr, Yip R. Oski Iron Deficiency and Related Nutritional Anemias. In; Notan DG, oski FA (eds) Hematology of Infancy an Childhood (5th ed) Philadelphia: WB Sounders 1998: 430-76

2. Dilek I, Altun S, Tuncer I, Uygan I, Topal C, Aksoy H. Demir eksikliği anemisinde hemoglobin, hematokrit değerleri, eritrosit indeksleri ve etiyolojik nedenlerin değerlendirilmesi. Van Tıp Fak Derg. 2000;7(2):51-6. 
3. Freire WB. Strategies of the Pan American Health Organization/ World Health Organization for the Control of Iron Deficiency in Latin America. Nutr Reviews 1997;55:183-8.

4. Benoist BD, McLean E, Egll I, Cogswell M. Worldwide prevalence of anaemia 1993-2005: WHO global database on anaemia. Geneva: WHO global database on anaemia; 2008.

5. Gür E, Yildiz I, Celkan T, Can G, Akkus S, Arvas A, Güzelöz S, Cifçili S Prevalence of anemia and the risk factors among schoolchildren in Istanbul. J Trop Pediatr. 2005;51(6):346-50.

6. Worldwide prevalence of anaemia 1993-2005. WHO Global Database on Anaemia. Geneva, World Health Organization, 2008. (available at https://apps.who. int/nutrition/publications/micronutrients/anaemia_iron_ deficiency/9789241596657/en/inde x.html).

7. Iron deficiency anemia: assessment, prevention and control. A guide for programme managers. Geneva, World $\mathrm{H}$ e a I t h
Organization, $2001 \quad$ (WHO/NHD/01.3). ( a v a i l a b l e at https://apps.who.int/nutrition/publications/micronutrients/ anaemia_iron_deficiency/WHO_NHD_01.3/en/index.html deficiency/WHO_NHD_01.3/en/index.html).

8. Yılmaz E, Doğan Y, Güngör $S$, Aydın M, Aygün D. 2-11 yaş grup çocuklarda demir eksikliği anemisi sıklığı. Klinik Bilimler ve Doktor. 2002; 8:481-5

9. Bahar A, Karademir F, Aral YZ, Göçmen I, Gültepe M. Çocuklardaki demir eksikliğinin tespitinde serum demiri ve eritrosit cinko protoporfirin/hem oranının yeri. Çocuk sağlığı ve Hastalıkları Derg 2003;46: 24-9.

10. Celkan T, Apak H, Özkan A at al. Demir eksikliği anemisinde önlem ve tedavi. Türk Pediatri Arşivi 2000; 35 (4).

11. Eren EÇ, Hatipoğlu S. Çocuklarda yaş gruplarına ve cinslerine göre anemi ve demir eksikliği anemisi sıklığının incelenmesi. Bakırköy Dr. Sadi Konuk Eğitim ve Araştırma Hastanesi Çocuk Sağlığı ve Hastalıkları Klinik Bölümü. Uzm. Tezi 2008.

12. Kwiatkowski JL, West TB,Heidary N, Smith-Whitley K,Cohen AR. Severe iron deficiency anemia in young children. J Pediatr 1996; 129:382-9.

13. Kaya Z, Gürsel T , Bozkurt R, Kocak Ü , Aral Y . Çocuklarda anemi sıklığı ve enfeksiyon anemi ilişkisi. Ege Tıp Derg 2007;46(1):37-40.

14. Isıık Balcı Y, Karabulut A, Gürses D, Ethem Cövüt I. Prevalence and Risk Factors of Anemia among Adolescents in Denizli, Turkey. Iran J Pediatr 2012;22:77-81.

15. Karagün BŞ, Korkmaz Ö, Gürsu $\mathrm{AH}$ et al. Sivas ilinde hastaneye başvuran 1-15 yaş grubu çocuklar arasında anemi prevalansı. Güncel Pediatri. 2014;2:67-72

16. Karakurt N, Terzi Ö. Prevalence of Anemia Among Children in a Single University Hospital İzmir Dr. Behçet Uz Çocuk Hast. Derg 2019;9(2):155-9

17. Meral G, Uslu A, Akçay F, Erzurumlu E. İstanbul Kağıthane Devlet Hastanesi'nde 1-12 yaş grubu erkek çocuklarında anemi sıklığının değerlendirilmesi, Şişli Etfal Hastanesi Tıp Bülteni 2011;45(4):130 3.

18. De Maeyer E, Adiels-Tegman M. The prevalence of anemia in the world. World Health Stat Q 1985;38:302-16

19. Karaoğlu L, Omaç M, Özen G, Türkol E. Malatya il Merkezinde Yaşayan 2-5 Grubu çocuklar ve Annelerinde Anemi Prevalansı ve Diyetle ilişkisi. 12thWorld Public Health Congress 27 Nisan - 01 Mayıs 2009, İstanbul.

20. Özdemir N. Çocuklarda demir eksikliği anemisi. Türk Pediatri Arşivi 2015;50:11-9.

21. Koç A, Kösecik M, Vural H, Erel O, Ataş A, Tatli MM. The frequency and etiology of anemia among children 6-16 years of age in the southeast region of Turkey. Turk J Pediatr. 2000;42(2):91-5.

22. Akman M, Cebeci D, Okur V, Angin H, Abali O, Akman AC. The effects of iron deficiency on infants' developmental test performance. Acta Paediatr. 2004;93(10):1391-6.

23. Vatandaş N, Atay G, Tarcan A, Kanra S, Özbek N. Hayatın ilk yılında demir profilaksisi ve anemi. Çocuk Sağlığı ve Hastalıkları Dergisi 2007;50:12-5 